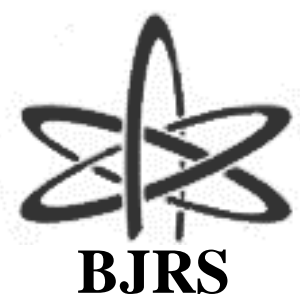

BRAZILIAN JOURNAL $\mathrm{OF}$ RADIATION SCIENCES 07-02B (2019) 01-14

\title{
Artificial neural networks for spatial distribution of fuel assemblies in reload of PWR reactors
}

\author{
E. C. A. Oliveira, V. F. Castro, P. A. L. Reis, C. Pereira \\ Departamento de Engenharia Nuclear/Universidade Federal de Minas Gerais /Av. Pres. Antônio Carlos, 6627/31270- \\ 901 Pampulha, Belo Horizonte, MG. \\ edyene.oliveira@ufmg.br;claubia@nuclear.ufmg.br
}

\begin{abstract}
An artificial neural network methodology is being developed in order to find an optimum spatial distribution of the fuel assemblies in a nuclear reactor core during reloading. The main bounding parameter of the modeling was the neutron multiplication factor, $k_{\text {eff. }}$ The characteristics of the network are defined by the nuclear parameters: cycle, burnup, enrichment, fuel type, and average power peak of each element. As for the artificial neural network, the ANN Feedforward Multi_Layer_Perceptron with various layers and neurons were constructed. Three algorithms were used and tested: LM (Levenberg-Marquardt), SCG (Scaled Conjugate Gradient) and BayR (Bayesian Regularization). The artificial neural network has implemented using MATLAB 2015 a version. As preliminary results, the spatial distribution of the fuel assemblies in the core using a neural network was slightly better than the standard core.
\end{abstract}

Keywords: Artificial Neural Networks, Computational Intelligence, Nuclear Reactors, PWR. 


\section{INTRODUCTION}

The fuel reload of a nuclear reactor includes operational and safety restrictions. It is a process involving the insertion of fuel elements with varied enrichment. Some assemblies already contain partially irradiated fuel, while others contain fresh fuel, besides those that have a mixture of burnable poisons. For these reasons, the spatial distribution of the fuel elements in the core influences the behavior of the reactor. The fuel elements with higher burnup have fewer reactivity than another new element, for example. In view of this, when inserting two or more elements with high-level of burnup, together there may be a power outage in that core region. Whereas two or more new elements inserted together tend to increase power in a certain region, which is not adequate $[3,5,7]$.

In addition, there is still a concern in the optimization of the fuel elements in the core. It is safe to say that, by reducing the costs of the reactor operation, the cost of electricity production is also reduced [3].

This work goal is to identify an acceptable reload standard for a PWR (Pressurized Water Reactor) core so that minimizes the fuel burnup, thus extending the burnup. There are several published works where the authors conducted tests using modern algorithms such as the evolutionary, heuristic and artificial neural networks (ANN). However, by the time, due to the expensive computational resources, no solution was implemented that could present a reload pattern with the characteristics desired above for any reload set.

Artificial neural networks are used to receive a set of fuel elements composed by $1 / 4$ of the PWR core out of the standard and, after processing, they are able to generate a dataset with a satisfactory spatial distribution. This means that the output proposed by the ANN model will be tested by a nuclear code system to calculate and obtain nuclear data to serve as parameters to validate the ANN output. The choice of this technology was due to the success achieved in difficult-solving problems. Currently, artificial neural networks have been used for some time to predict, extract, classify, and group data [14]. In recent years, work with artificial neural networks has gone beyond, being widely used in electronic games, identification of images, texts and voice, to name just a few. On the next section, some correlated works are presented. Next, artificial neural networks are briefly described. Then the methodology adopted will be detailed, as well as the results of the experiments. And finally, considerations will be made on the proposed solution. 


\section{MATERIALS AND METHODS}

\subsection{ARTIFICIAL NEURAL NETWORK}

Artificial neural networks (ANN) process information differently than a traditional computer. ANN has the fitness to them, making them able to solve complex problems such as pattern recognition [21].

A traditional computer system cannot resolve simple tasks like some that are performed by animals, such as recognition of a familiar face in an unknown scenario. The brain has a learning capability, and, in humans, this phase happens with greater intensity in the first two years of life. However, the process goes well beyond, practically in the entire life of the individual [14]. Artificial neural networks have similar traits, so they can learn from experience, as well as the biological brain. Next sections will present neural, feedforward architecture and backpropagation training algorithm.

\subsection{ARTIFICIAL NEURON}

The first model of ANN (Artificial Neural Network) arose around 1946 with McCuloch and Pitts [22]. Scientists proposed the first artificial neuron as can be verified in Figure 1.

Figure 1: Artificial Neuron Model

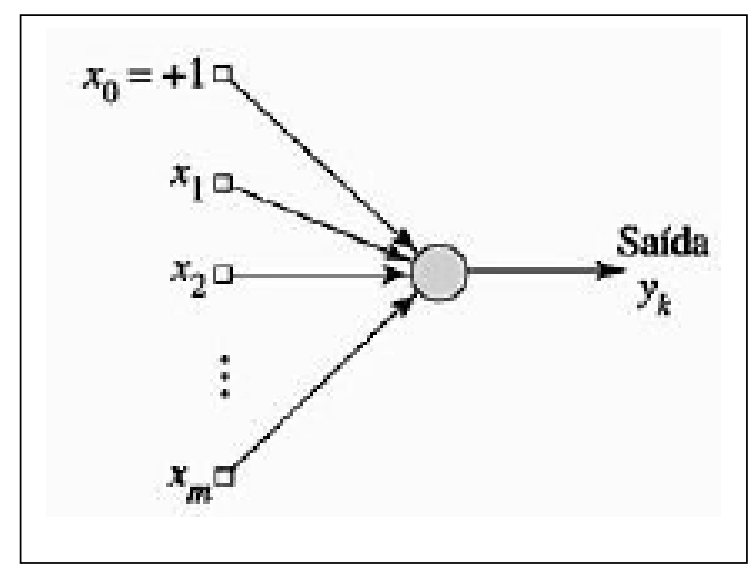

Source: Haykin (2009) 
The model was composed of a processor unit represented in Figure 1 by the filled or colored circle. The entries or data to be processed are characterized by squares starting with $\mathrm{X}_{1}, \mathrm{X}_{2} \ldots \mathrm{X}_{\mathrm{m}}$. The output is represented only by $\mathrm{Y}_{\mathrm{k}}$. The first square $\mathrm{x}_{0}=+1$ corresponds to the bias, for instance, it is an entry that always receives value 1 . The purpose of this differentiated entry assists in processing the data.

ANN is formed by several brain cells and layers. The quantity is defined according to the complexity of the problem [14]. Figure 2 shows an ANN model.

Figure 2: Artificial Neural Network Model

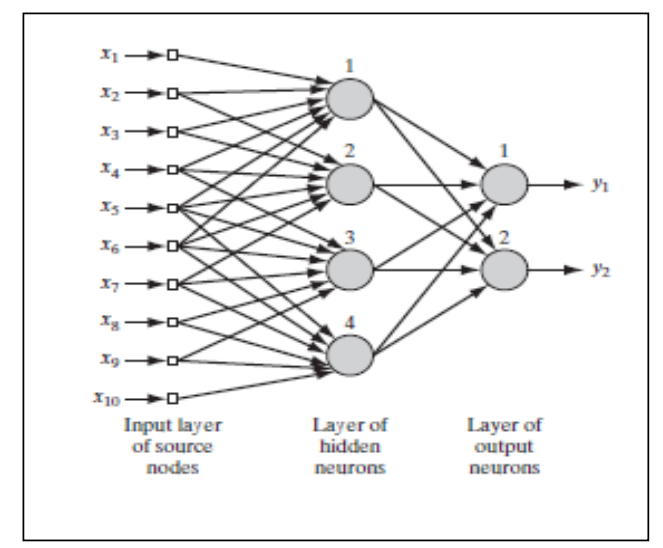

Source: Haykin (2009)

Figure 2 shows an artificial neural network with an input layer, a layer hidden, and a layer output. The choice of architecture besides depending on the complexity of the problem should also consider learning algorithm. There are several algorithms that can be used, the traditional is the backpropagation [21].

\subsubsection{LEARNING ALGORITHM}

Learning algorithms are structured programs that aim to assist in the learning of ANN. They have two main features, namely, learning algorithms can be or not supervised.

A supervised algorithm is the one that receives input and output data for processing. With this, ANN during a stage called training knows the input and output [14]. 
Unsupervised algorithms do not receive output, only the input. Therefore, they do not know the nature of the data. Generally, these algorithms are used for grouping, for instance, they receive multiple data and organize them according to the identified characteristics [21].

The backpropagation algorithm is supervised, thereby, receives a vector with data in input to be computed and another vector with the corresponding responses. When arriving in the ANN output layer, the Backpropagation compares the output computed by ANN with the corresponding response that it received. If the results are different, for example, if ANN computed wrong, he stores the error and returns to the beginning of the ANN architecture, restarting processing.

For all commonly supervised algorithms, the initial dataset is separated into two sets. The first of them is for training, usually $80 \%$ of the total. The second set is used for validation [14]. This procedure appropriate because with $80 \%$ of total data, ANN will train, for instance, will receive the input, compute the output and compare to the answer. This is the training phase. However, necessary to perform tests to verify the learning, so the $10 \%$ separated previously has this purpose and last set is used for validation that is a parameter used by the ANN programmer to stop processing if ANN not learning [22]. Thus, while improvements are occurring, while ANN is computed as the input compared to the output, the process continues. In this case, the stop parameter will be the amount of processing stipulated by the programmer. Otherwise, if ANN reaches the stipulated quantity for validation without improving the learning, the ANN stops processing. This parameter will prevent the ANN from performing all tests without reaching the goal. In some cases, the performance can be around $20 \%$ or $30 \%$ of the training. The ideal, in this case, is to stop [23].

\subsubsection{LEARNING PROCESS}

ANN of type MultiLayer Perceptron can contain N connections to represent the $\mathrm{N}$ input variables. An example of input vector could be $\left\{\mathrm{x}_{1}, \mathrm{x}_{2} \ldots \mathrm{X}_{\mathrm{n}}\right\}$. The corresponding weight vector, w, would be $\left\{\mathrm{w}_{1}, \mathrm{w}_{2}, \mathrm{w}_{3}, \ldots \mathrm{w}_{\mathrm{n}}\right\}$. The response of the processing represented by the letter $u$ in equation 1 below would be [21]:

$$
u=w_{1} x_{1}+w_{2} w_{2}+\cdots+w_{n} x_{n}
$$

The threshold function defined in the source produces a $y$ - output, so that: 


$$
y= \begin{cases}0, & u<0 \\ 1, & u \geq 0\end{cases}
$$

If ANN response is correct so that computed values are equal to those received, the weight vector is not adjusted. Otherwise, the individual weights are adjusted using a Perceptron learning algorithm, which is a modified form of Hebbian learning that incorporates the error as follows [22]:

$$
\text { Error }=E=t-y
$$

Where's $\mathrm{T}$ is the expected exit. The weights vector is upgraded to equation 4.

$$
w_{\text {new }}=w_{\text {old }}+\beta x E
$$

Where $w_{\text {new }}$ is the new weight value, $w_{\text {old }}$ is the value of the old weight, $x$ is the input vector and $\beta$ is the learning rate. This is a constant between 0 and 1 that aims to adjust the learning speed. When $\beta$ has a lower value, the adjustment occurs slower and so, the training time will be longer. While using higher values, learning will accelerate.

Accelerating learning does not mean better performance because it can cause instability. The algorithm jumps in wide steps oscillating around optimal points, without yet reaching them [21].

\section{METHODOLOGY}

\subsection{Obtaining Data}

An ANN learns using a stochastic optimization algorithm, as is the case of backpropagation and its variations. Therefore, a large amount of data is required for training. The size of the data set depends on the complexity of the problem. However, according to the literature, the more data, better [14]. 
For this work, 70 sets of PWR reactor core $1 / 4$ validated by the PARCS ${ }^{1}$ nuclear code were used. Each set consisted of 20 characteristics of the combustible elements and their positions, as well as information of the core geometry. The clusters were obtained through the ANN itself. As it was presenting results deemed appropriate, these were validated by the nuclear code and then inserted into the model training set in order to further improve it.

The whole process worked as follows: In order to generate a method that could be repeated was developed a computational system to present a set of data for ANN, then extract the response and generate the input to be validated by the code Nuclear PARCS. After validation, the system sought the exit of the PARCS and performed another validation based on certain criteria, such as $\mathrm{k}_{\text {eff }}<=$ 1.10 and the 5 highest relative power peaks lower than 1.6. If the system response was acceptable, the set was part of the training group. Figure 3 shows the generated method for obtaining the data, processing it in the ANN, and validating it in the PARCS.

Figure 3: Process to Assist RNA Converging

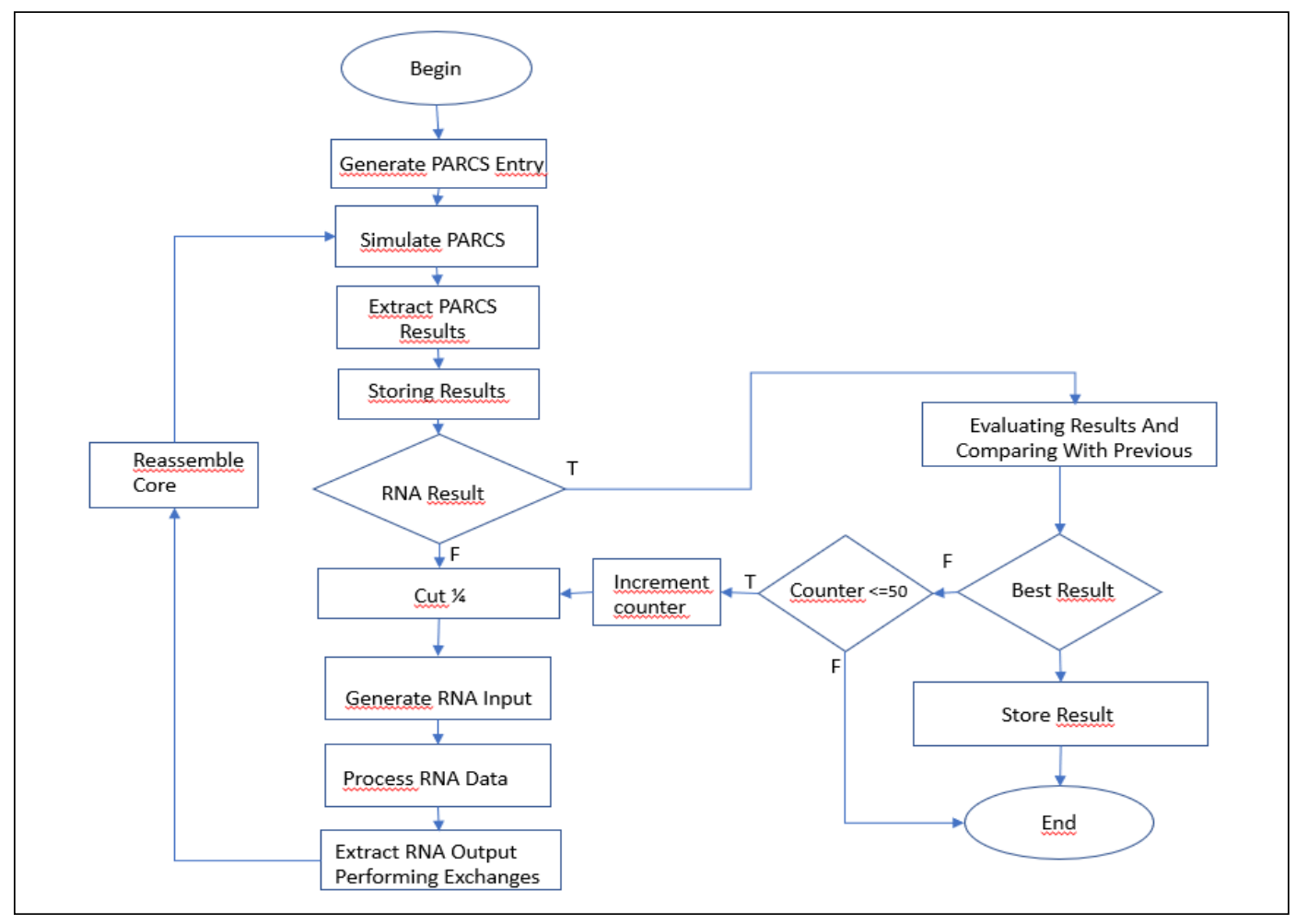

${ }^{1}$ https://engineering.purdue.edu/Engr/AboutUs/Facilities/NE/PARCS 


\subsection{ANN Training}

Each data set was separated int other parts, being $80 \%$ used for ANN training, the remainder for validation. Each data set consisted of 56 rows of data, i.e. 56 x 70 sets. Therefore, the complete set consisted of 3,920 information or data line.

Of the total 3,136 data were used for training. The remainder of the data was used for ANN validation. All data were normalized using the Min/Max function. Equation 5 shows the normalization used [23].

$$
x_{T i}=\frac{x_{i}-x_{\text {imin }}}{x_{\text {imax }}-x_{\text {imin }}}
$$

where $x_{\text {imin }}$ and $x_{\text {imax }}$ are the minimum and maximum values of the $x_{i}$ variable.

To perform the tests that, in this case, means to evaluate the accuracy of ANN after training, 3 sets of data were used. These sets totaled 168 lines in total.

\subsubsection{ANN Validation}

In this work, the cross-validation method was used. It is a process where a reserved set is divided into a certain quantity and each time one of these parts is tested in ANN. This data used for validation is not part of the training set, so they are unknown by the model.

In each training step, a subset of the validation set is confronted with the ANN result. This is done by presenting an example of the validation for the ANN and the predicted result is compared with the actual result. Thus, all results are counted to verify the accuracy of ANN.

\subsubsection{ANN Tests}

After completion of the ANN training, the test set is used to verify the performance of the trained ANN. This work, after ANN training, the model received three sets of data containing the equivalent of core $1 / 4$, that is, 56 rows of data. The after process performed by ANN, the response was captured, the exchanges performed and then validated by the nuclear PARCS code. 
The response of the PARCS, which are the safety values used in this work, keff and relative power peaks were compared with the values prior to the process. The result considered appropriate was accounted for or discarded if it was worse than the previous one.

\subsection{Materials and Methods}

The ANN code was implemented in the MATLAB 2018a. The model was built with 20 characteristics in the input layer, two hidden layers, the two with 50 neurons and the output layer with only 1 neuron.

The activation function used was the hyperbolic tangent in the first layer, ReLu in the second and the output layer has not used any function. The learning rate that helped in the proper convergence had a value of 0.010 .

\section{RESULTS AND DISCUSSION}

The accuracy of ANN was measured in the training by accounting for the correct output values compared to the predicted value with the actual value. As a supervised model, both the characteristics and the response were passed on to the ANN. So, it had to compare the actual value with the predicted making notes of the errors and hits. The learning algorithm used was the Backpropagation with three variations, the first being Levemberg (LM), the second the Bayesian (Bayr) and the third the Conjugated Scaled (SCG). In the training, the results ranged from $36 \%$ to $92 \%$ of accuracy, as can be seen in Table 3.

Table 3: Results of Experiments in the Training Phase

\begin{tabular}{ccc}
\hline Algorithm & Neurons & Performance \\
\hline \multirow{2}{*}{ LM } & 100 & $78 \%$ \\
& 250 & $83 \%$ \\
BayR & 500 & $86 \%$ \\
\hline \multirow{2}{*}{ Bar } & 100 & $79 \%$ \\
\end{tabular}




\begin{tabular}{ccc} 
& 500 & $\mathbf{9 2 \%}$ \\
\hline \multirow{3}{*}{ SCG } & 100 & $36 \%$ \\
& 250 & $40 \%$ \\
& 500 & $60 \%$ \\
\hline
\end{tabular}

With the trained model, tests were performed with data sets unknown by ANN. This phase indicates whether the neural network has learned and can be used in production. Three sets were used, and for each case, the $k_{\text {eff }}$ and the highest relative power peak value was recorded in order to compare with the result at the end of the process. The results presented by the ANN were validated by the PARCS results and then compared with the previous results. The images $4 \mathrm{a}$ to $6 \mathrm{a}$ present the results obtained the trained model, i.e. in the test phase.

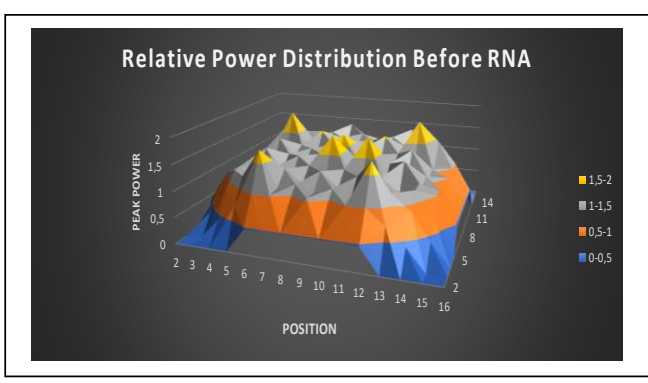

Figure 4a: Case 1- Relative Power Distribution Before RNA. k-effective: 1.0976 Highest relative power peak: 1.52

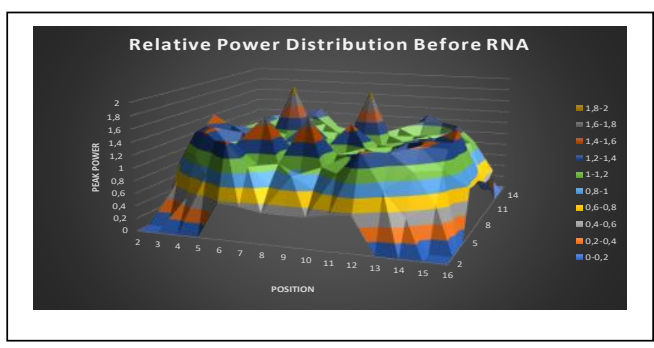

Figure 5a: Case 2- Relative Power Distribution Before RNA. k-effective: 1.1016 Highest relative power peak: 1.55

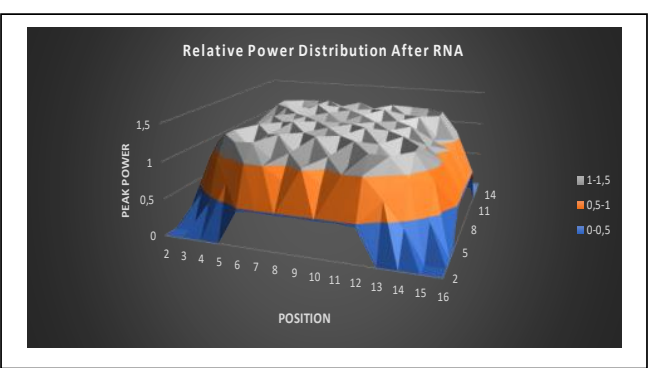

Figure 4b: Case 1 - Relative Power Distribution After RNA. k-effective: 1.093 Highest relative power peak: 1.39

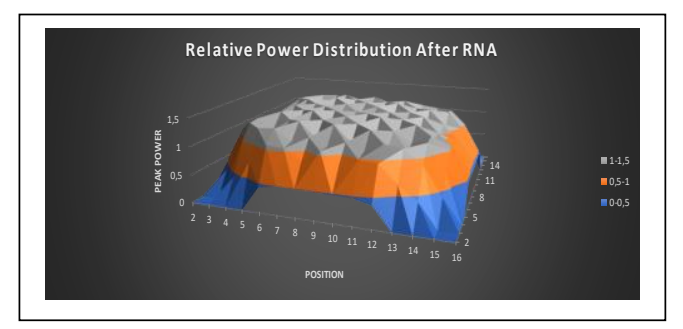

Figure 5b: Case 2 - Relative Power Distribution After RNA.

k-effective: 1.0943

Highest relative power peak: 1.32 


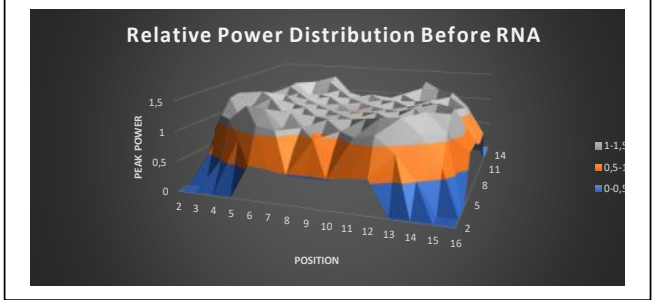

Figure 6a: Caso 3 - Relative Power Distribution Before RNA.

k-effective: 1.112

Highest relative power peak: 1.52

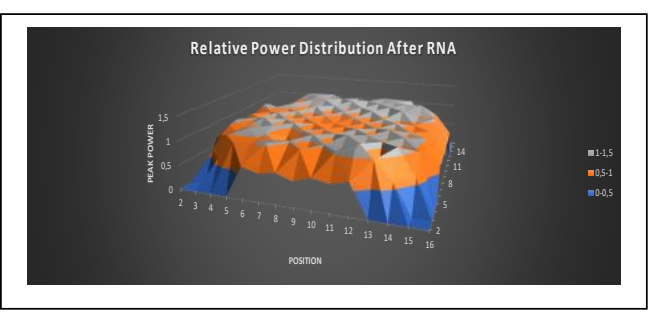

Figure 6b: Case 3 - Relative Power Distribution After RNA.

k-effective: 1.0912

Highest relative power peak: 1.15

Optimizing a set of data from a reactor is considered a complex problem, because when performing an exchange, the peak of the relative power of the fuel element is changed, from the neighbors and, consequently, from the whole nucleus. In addition, the number of combustible elements in the core, as in the case of Angra 2 contributes making it even more difficult. In this article, an ANN was implemented in order to optimize the core of a PWR reactor.

As seen in this article, an ANN learns from examples. Thus, two sets of datasets generated, being $80 \%$ for training and the remainder for validation. Next, an ANN model was developed with three different learning algorithms and Bayesian presented results above $90 \%$ in the trainings.

In the tests, the trained ANN suggested exchanges that when applied resulted in an optimized set. In this article only 3 results were presented, however, the trained model was able to optimize 8/10 unknown sets.

In future works, other technologies are also suggested, such as deep learning. These are modern techniques that have obtained satisfactory results in several fields, especially unknown data.

\section{ACKNOWLEDGMENT}

The authors are grateful to the Brazilian research funding agencies, CNEN (Comissão Nacional de energia Nuclear), CNPq (Conselho Nacional de Desenvolvimento e Pesquisa), CAPES (Brazil) and FAPEMIG (Funadação de Amparo à Pesquisa do Estado de Minas Gerais) for the support.

\section{REFERENCES}


1. AUGUStO, C. S. P. JOÃO, NICOLAU, S. ANDRESSA, SCHIRRU, ROBERTO. PSO with Dynamic Topology and Random Keys method applied to Nuclear Reactor Reload, Brazil, 2015, Vol. 83, pp. 191-196.

2. BABAZADEH, DAVOOD, BOROUSHAKI, MEHRDAD, LUCAS CARO. Optimization Of Fuel Core Loading Pattern Design In: VVER Nuclear Power Reactors Using Particle Swarm Optimization (PSO), 2009, Iran, Elsevier, vol. 23, pp. 923-930.

3. CACUCI, D.G. Handbook of Nuclear Engineering, Springer Verlag, Alemanha, 2013.

4. CHAPOT, L. C. JORGE, SILVA, C. FERNANDO, SCHIRRU, ROBERTO. A New Approach to the Use Of Genetic Algorithms to Solve the Pressurized Water Reactor's Fuel Management Optimization Problem, Brazil, 1999, Pergamon, Vol. 26, pp. 641-651.

5. COCHRAN, Robert G. Tsoulfanidis, Nicholas. The Nuclear Fuel Cycle: Analysis and Management, American Nuclear Society, 1999.

6. CHUNHUI DAI, XINYU WEI, YUN TAI, FUYU ZHAO, The Optimum Design of Power Distribution For Pressurized Water Reactor, China, 2012, Vol. 50, pp. 126-132.

7. DUDERSTADT, James and Louis J. Hamilton. Nuclear Reactor Analysis, Wiley, NY, 1976.

8. ERDOGAN, ADEM MELIH, GEC. A PWR Reload Optimization Code Using Artificial Neural Networks and Genetic Algorithms, Turkey, 2003, Elsevier, Vol. 30, pp. 35-53.

9. FARIA, EDUARDO FERNANDES, Otimização da Distribuição Espacial de Combustíveis Reprocessados Utilizando Técnicas de Redes Neurais, Dissertação, Ciências Técnicas Nucleares da Universidade Federal de Minas Gerais, Brazil, 1999.

10. FARIA, F. EDUARDO, PEREIRA, CLAUBIA. Nuclear Fuel Loading Pattern Optimization Using A Neural Network, Brazil, 2003, Pergamon, Vol. 30, pp. 603-613.

11. FOSTER, Artur R., Basic Nuclear Engineering, Third Edition, 1977.

12. GLADSTONE, Samuel. Ingenieria de Reactores Nucleares, Editorial Reverté, Barcelona, 1975. 
13. GONZALVEZ, JOSÉ. Sensitivity study on e termining an efficient set of fuel assembly parameters in training data for designing of neural networks in hybrid genetic algorithms, Spain, 2005, Elsevier, Vol. 33, pp. 457-465.

14. HAYKIN, Simon. Neural Networks and Learning Machines, $3^{\mathrm{a}}$ edição, New Jersey, Prentice Hall, 2009.

15. LEWIS, Elmer E. Fundamentals of Nuclear Reactor Physics, Academic Press, $1^{\mathrm{a}}$ edição, 2008.

16. NICOLAU, S. ANDRESSA, SHIRRU, ROBERTO, LIMA, M. M.,ALAN. Nuclear Reactor Reload Using Quantum Inspired Algorithm, Brazil, 2012, Elsevier, Vol. 55, pp. 40-48.

17. OLIVEIRA, M. IONÁ, SCHIRRU, ROBERTO. Swarm Intelligence of Artificial Bees Applied To In-Core Fuel Management Optimization, Brazil, 2011, Vol. 38, pp. 1039-1045.

18. ORTIZ, J. JOSE, REQUENA, IGNACIO. Using A Multi-State Recurrent Neural Network To Optimize Loading Patterns In Bwrs, Spain, 2004, Elsevier, Vol. 31, pp. 789-803.

19. POURSALEHI, N, ZOLFAGHARI, MINUCHEHR. Multi-Objective Loading Pattern Enhancement Of PWR Based on the Discrete Firefly Algorithm, Teerã, Elsevier, 2012, Vol. 57, pp. 151-163.

20. POURSALEHI, N., ZOLFAGHARI, A., MINUCHEHR, A., MOGHADDAM,H.K. Continuous Firefly Algorithm Applied to PWR Core Pattern Enhancement, Teerã, Elsevier, 2012, vol. 258, pp.107-115.

21. REZENDE, Solange Oliveira. Sistemas Inteligentes - Fundamentos e Aplicações, São Paulo, Manole, 2005.

22. RUSSELL, Stuart; Norvig, Peter. Artificial Intelligence - A Modern Approach, Third Edition, New Jersey, Prentice Hall Series em Inteligência Artificial, 2010.

23. SAMARASINGHE, Sandhya. Neural Networks for Applied Sciences and Engineering: From Fundamentals to Complex Pattern Recognition, New Jersey, Auerback Publications, 2007. 
24. SHICHANG LIU, JIEJIN, CAI. Studies of Fuel Loading Pattern Optimization For a Typical Pressurized Water Reactor (PWR) Using Improved Pivot Particle Swarm Method, Brazil, 2012, Elsevier, Vol. 50, pp.117-125.

25. SILVA, H. MÁRCIO, SCHIRRU, ROBERTO. A Self-Adaptive Quantum PBIL Method For The Nuclear Reload Optimization, Brazil, Elsevier, 2014, vol. 74, pp. 103-109.

26. SILVA, H. MÁRCIO, SCHIRRU, ROBERTO, LIMA, M. M. ALAN. QACO_Alpha applied to the nuclear reactor core fuel reload optimization, Brazil, 2011, Elsevier, Vol. 53, pp. 80-85.

27. SOUZA, M. ROSE, MOREIRA, JOÃO. Neural network correlation for power peak factor estimation, Brazil, 2006, Elsevier, Vol. 33, pp. 594-608.

28. STOUT, B. RICHARD, Optimization Of In-Core Nuclear Fuel Management In a Pressurized Water, Thesis/Dissertation, Oregon State University, 1972.

29. TAVARES, ODILON A. P. Energia Nuclear: ontem e hoje, Revista Ciência Hoje, edição 299, 2013. Last accessed: 18/11/2017.

http://www.cienciahoje.org.br/revista/materia/id/689/n/energia_nuclear:_ontem_e_hoje. 